\title{
Asystole by ECG Finding
}

National Cancer Institute

\section{Source}

National Cancer Institute. Asystole by ECG Finding. NCI Thesaurus. Code C116130.

An electrocardiographic finding showing no cardiac electrical activity on the monitor or

printed strip for the entire duration of the recording. (CDISC) 